\title{
A Confusão de Línguas e os Desafios da Psicanálise de Grupo em Instituição
}

\author{
The Language Confusion and the \\ Challenges of Group in Institutions
}

La Confusión de Lenguas y Los Desafíos del Psicoanálisis de Grupo en Institución
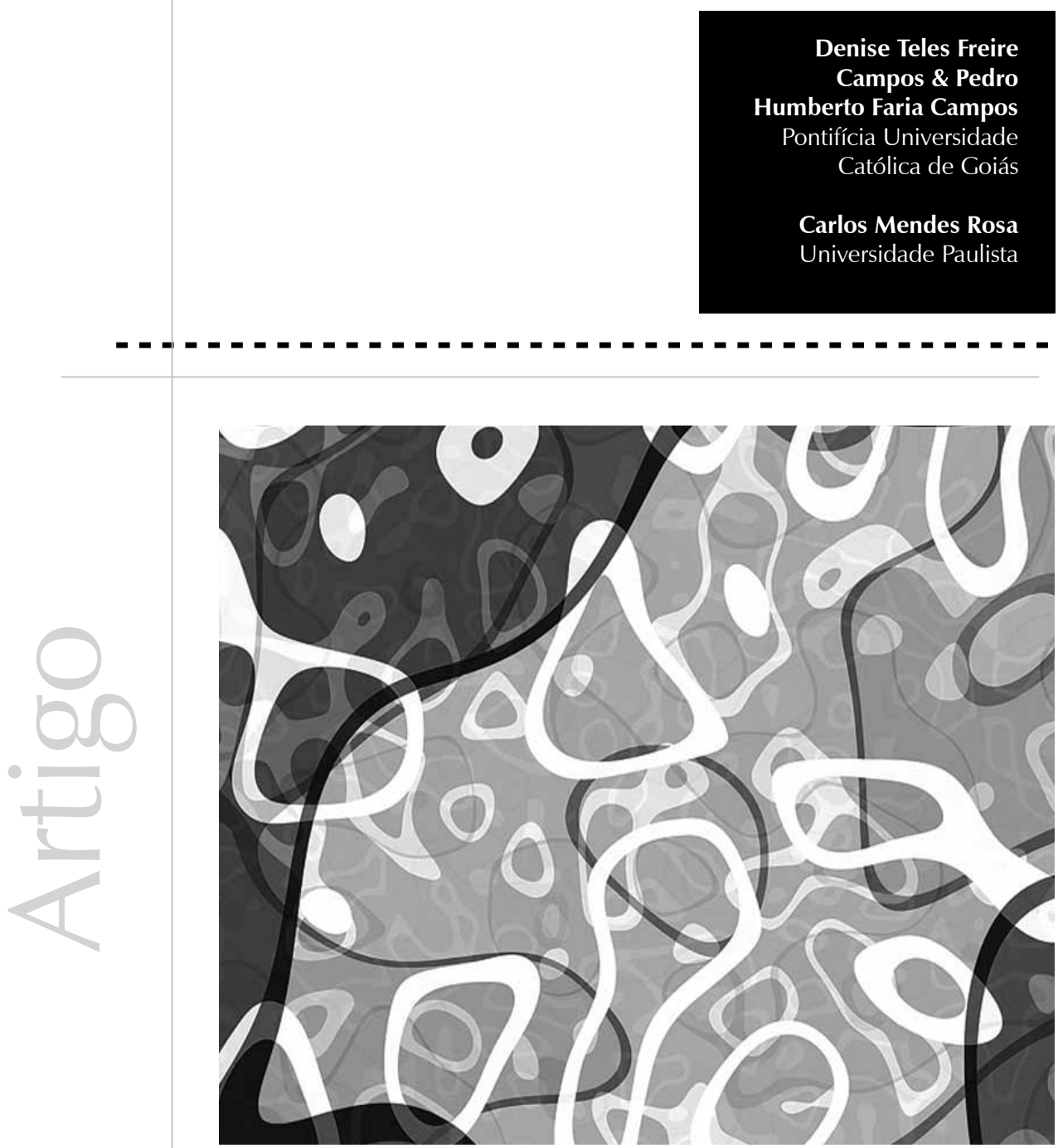
Resumo: Este trabalho é uma reflexão sobre os desafios da psicanálise de grupo na instituição. O texto faz uma análise do contexto institucional desde a reforma psiquiátrica, que buscou o enfrentamento da exclusão social, como processo sociohistórico e simbólico que atinge a identidade do portador e a dos familiares. Assim, a relação entre o cuidado com o sofrimento e a assistência à exclusão é discutida sob o prisma da integração e da revalorização da dimensão clínica do tratamento. A distinção entre demanda, necessidade e desejo é retomada para apontar a importância de manter o sujeito portador no centro do modelo. Em seguida, examina-se a confusão de línguas entre psicanálise, psicoterapia e psiquiatria, apontando algumas das principais questões clínicas e sociais relativas ao atual fazer do analista. O presente trabalho se funda na reflexão sobre o trabalho de grupo em instituição, inspirada em atendimentos semanais a três grupos de pacientes de um CAPS, e coloca a transferência e a mediação grupal como dispositivos necessários para o trabalho em grupo. A psicanálise de grupo é sustentada como forma de elaboração do sofrimento psíquico, redirecionando a própria noção de sujeito.

Palavras-chave: Instituição pública. Saúde mental. Psicanálise de grupo. Grupo.

Abstract: This work is a reflection about the chalenges of group psychoanalysis in institutions. The text analyses the institutional context since the psychiatric reform, which sought to confront the social exclusion, as a simbolic and social-historical process that involves the identity of the carrier and of his/her family. So, the relation between "care with suffering" and the assistance to the exclusion are discussed based on the integration and revalorization of the clinic dimension of the treatment. The distinction between "demand, necessity and desire" is retaken to point out the importance of keeping the carrier subject in the center of the model. Then the language confusion between psychoanalysis, psychotherapy and psychiatry is examined, pointing out the main clinic and the social matters related to the actual work of the analist. The present work is based on the reflection about the group work in institutions, inspired in weekly attendance to three patient groups of a psycho-social attention center (CAPS) and it places the transference and the groupal mediation as necessary devices to the group work. The group psychoanalysis is sustained as a form of elaboration of psychological suffering, redirecting the very notion of subject.

Keywords: Community mental health centers. Mental health. Group Psychoanalysis. Group.

Resumen: Este trabajo es una reflexión sobre los desafíos del psicoanálisis de grupo en la institución. El texto hace un análisis del contexto institucional desde la reforma psiquiátrica, que buscó el enfrentamiento de la exclusión social, como proceso socio-histórico y simbólico que alcanza la identidad del portador y la de los familiares. Así, la relación entre el cuidado con el sufrimiento y la asistencia a la exclusión es discutida bajo el prisma de la integración y de la revalorización de la dimensión clínica del tratamiento. La distinción entre demanda, necesidad y deseo es retomada para apuntar la importancia de mantener el sujeto portador en el centro del modelo. En seguida, se examina la confusión de lenguas entre psicoanálisis, psicoterapia y psiquiatría, apuntando algunas de las principales cuestiones clínicas y sociales relativas al actual hacer del analista. El presente trabajo se funda en la reflexión sobre el trabajo de grupo en institución, inspirada en atendimientos semanales a tres grupos de pacientes de un CAPS, y coloca la transferencia y la mediación grupal como dispositivos necesarios para el trabajo en grupo. El psicoanálisis de grupo es sustentado como forma de elaboración del sufrimiento psíquico, re-direccionando la propia noción de sujeto.

Palabras clave: Centros comunitarios de salud mental. Salud mental. Psicoanálisis de Grupo.Grupo.-

O presente trabalho tem por objetivo discutir os desafios de um modelo de psicoterapia psicanalítica de grupo em instituição pública, notadamente dentro dos serviços de atenção especial, inaugurados a partir da reforma psiquiátrica. Assim, o trabalho visa também a contribuir para o processo de consolidação metodológica e terapêutica do novo paradigma de assistência instalado. Para tal, buscaremos discutir a noção de causalidade psíquica, a confusão de línguas entre as áreas científicas que trabalham com o sofrimento psíquico ou com os chamados transtornos e a necessária distinção entre demanda, desejo e necessidade no âmbito das instituições públicas, além de apontar alguns aspectos práticos das experiências e dos desafios da atuação do psicanalista nesse campo e o contexto histórico específicos.

Os autores aqui tomam uma posição favorável à dimensão grupal e ao trabalho de terapia 
de grupo como recursos metodológicos incontornáveis. Isso se coloca não como oposição à psicanálise individual, tampouco postulando que o grupo pudesse ser superior a outras modalidades de intervenção. Não se trata de uma reverberação no sentido de incitar terapeutas e profissionais do cuidado (quaisquer que sejam suas abordagens teóricas) a trabalhar com grupos, porque, nas instituições públicas, as condições de atendimento não são suficientes para atender toda demanda quantitativa. Em uma vertente distinta, a posição em favor do grupo se sustenta em uma clareza conceitual, com base no conceito de exclusão social, como processo sociohistórico e simbólico que atinge de entrada a identidade do portador e a dos familiares. Nesse sentido, o palco por excelência de processos de transformação da identidade é a relação de alteridade, cujo espaço privilegiado é a mediação grupal. Como veremos adiante, o desafio do trabalho de grupo psicanalítico é compreender a superposição dos processos de transferência com aqueles de mediação grupal. Essa postura se inscreve organicamente em uma visão segundo a qual toda doença mental, independentemente das causas de sua eclosão ou emergência (genética, psicossocial, afetiva, etc), sofre de imediato também um processo de determinação social, isso porque, uma vez que um transtorno de ordem mental eclode, será objeto de processos de ordenamento, classificação, estigmatização e/ou exclusão. Esses processos citados recebem, sem dúvida alguma, o qualificativo de sociais.

Assim, existem ao menos duas formas de se compreender as consequências de tal visão, que não são, a nosso ver, excludentes entre si. Na vertente inspirada por Pichón-Rivière, o grupo tem como operador a identidade: a emergência da tarefa e sua transformação em projeto de vida, em superação da doença, é operada por um trabalho terapêutico de resgate da cultura e da partilha de identidades. Esse processo tem por base o grupo original (família) e os fantasmas inconscientes que dele derivam. Uma outra forma é compreender que, uma vez que a "'doença sofre' uma determinação social, ela produz o 'sintoma social', que se sustenta no 'laço social'", permitindo, desse modo, distinguir estrutura psíquica individual, de um lado, e uma sintomatologia que provém do laço social e sua inscrição no imaginário social de outro, tal qual o define Lacan. Nessa última perspectiva, o trabalho em grupo tem duas direções: contribuir para desconstruir o sintoma social, o que permitiria a emergência do singular, do desejo de cada um, e também permitir que o sujeito em sofrimento (o paciente dos CAPS, nesse caso) se re-situe, pela injunção de um modo de interpretação apropriado ao grupo e ao sintoma social, face aos objetos internos, difusos nas figuras fragmentárias dos substitutos do Outro, ou seja, do Outro do social.

O presente trabalho constitui uma reflexão sobre o trabalho de grupo em instituições, inspirada em atendimentos semanais a três grupos de pacientes de um CAPS da região central de Goiânia, desde 2007, sendo um grupo de acolhimento a novos usuários da instituição e dois grupos psicoterápicos. Os grupos psicoterápicos são formados por 10 pacientes em cada grupo, sendo esses sujeitos diagnosticados pela equipe médica como portadores de algum tipo de transtorno mental. Nos grupos atendidos, não existe a separação entre sujeitos com estruturas psíquicas diferentes; assim, temos psicóticos e neuróticos compartilhando suas experiências na mesma situação grupal. É interessante notar que os grupos psicoterápicos apresentam uma frequência às reuniões de aproximadamente $80 \%$.

O que se pretende apontar ao longo deste trabalho é o espaço vivo (o lugar antropológico) de contradição no qual devemos focar o sujeito, trazê-lo para o centro da cena, para o interior de instituições cujo funcionamento é destinado a apagar a incômoda singularidade do pathos. Pensar a psicanálise em instituição é repensar o valor da clínica na assistência.

A questão da causalidade psíquica e os transtornos mentais 
Sentimos de imediato que a culpa é um sentimento que tem alcance epistêmico: o "é minha culpa" implica uma hipótese sobre a causa. A culpa é aquilo que acontece quando a causa assume a forma de uma falha, um erro.

Collete Soller

A noção de causalidade psíquica é recente na história das ciências dedicadas ao estudo do psiquismo, especialmente nos campos da psiquiatria, da psicopatologia e, posteriormente, da própria Psicologia. Ela se refere à tendência do ser humano em atribuir causas internas, psicológicas, aos eventos que the acontecem. A causalidade psíquica distingue-se, em primeiro plano, das causalidades externas, tais como a causalidade divina ou social, porém ela distingue-se também daquelas internas associadas aos componentes propriamente biológicos ou genéticos. O diagnóstico da esquizofrenia, por exemplo, coloca sempre o problema da identificação inequívoca das causas, em que as noções de hereditário ou psicogênico traçam um embate, na maioria das vezes, infrutífero.

O conceito de causalidade psíquica é de origem psicanalítica. Ele nasce em contraponto a uma certa psicologia da consciência dominante no século XIX, que considerava a própria consciência função dominante no psiquismo; desse modo, o ser humano seria regido, sempre, pela razão e pela lógica, não se colocando assim a questão mesma do questionamento das causas: razões lógicas somente podem ser interrogadas a partir de argumentos, eles também, de natureza lógica. A noção de causalidade psíquica pressupõe que o sujeito seja a unidade das causas, portanto, não incita à identificação de causas isoláveis, externas ou internas, que se descolem do próprio sujeito. O termo mesmo tem por referente a subjetividade (manifestação do sujeito) e compreende a relação de causalidade como marcada, ao mesmo tempo, pelo corpo pulsional e pela cultura. Segundo Martins (2005), a novidade consiste em mostrar a implicação processual do eu com o inconsciente que o determina, mas o eu constitui obstáculo à satisfação pulsional. Não se trata de fazer o elogio da psicologia da consciência ou de qualquer psicologia do eu, mas de qualificar os efeitos dessa divisão. (p. 176)

Assim, podemos sintetizar a questão da causalidade psíquica da seguinte forma: não existe, para a psicanálise, uma causa única, isolável, objetivável para o sofrimento psíquico; ela é processual e subjetiva, e inscreve-se na interação entre o corpo pulsional e a cultura, ou seja, não há como investigar os transtornos sem o trabalho com o sujeito, sem permitir a manifestação e o desenvolvimento daquilo que há de singular em cada caso, da singularidade do sujeito. Deve-se salientar que, nos casos dos transtornos de causa orgânica identificável, ainda assim o objeto de cuidado será, do ponto de vista psíquico, o sofrimento advindo das determinações sociais das chamadas doenças mentais, sofrimento cuja causalidade é psíquica, ou seja, advém de uma discordância fundamental do sujeito consigo mesmo.

Como esse tema se articula com o atendimento psicanalítico em instituição? Melhor seria situálo em relação ao cuidado com o sofrimento psíquico em instituição. Apesar de a prática demonstrar que pacientes, familiares e profissionais de saúde na instituição chegam procurando uma resposta sobre a causa do transtorno que se abateu sobre o paciente ou usuário, essa causa não se mostra suficiente para resolver, por si só, os problemas dos que sofrem. E, ao analisarmos mais atentamente, percebemos que todos eles já têm uma resposta sobre a causa. Todos, público e nós, profissionais, já temos algumas respostas, já temos uma visão, uma representação da doença. Não por acaso, estudos recentes de representações sociais da doença mental revelam que os transtornos são representados como doença da cabeça, desequilíbrio, castigo de Deus ou obra do demônio, sem esquecer a ideia quase sempre presente de doença sem explicação. Não por acaso, Soller (2007) relembra que "o sentimento de culpa é o 
único que Freud consente em chamar de inconsciente" (p. 54).

Pereira (2000) remonta esse processo de chamada à responsabilidade por parte do sujeito aos tempos da Grécia antiga. No início existia a Até, conceito de loucura que se abatia sobre o homem por interferência dos deuses, ou seja, não passava pelo controle ou pela vontade do doente, e a este cabia apenas aceitar seu destino funesto. Mais tarde, a loucura passará a ser considerada uma consequência da hybris, ou do excesso de ambição por parte dos homens, levando a arrogância desmedida e a atos de insensatez. A noção de hybris leva embutida o caráter de envolvimento do sujeito no seu próprio sofrimento. Sua loucura agora pode ser associada ao seu mundo psíquico. É essa linha de pensamento que norteará a teoria de Freud sobre a psicopatologia do indivíduo.

O ponto é que as representações dos sujeitos envolvidos, sejam ingênuas ou especializadas, são insuficientes: produzem no próprio sujeito uma discordância consigo mesmo e geram sofrimento. A visão do sofrimento como de origem (causalidade) biológica ou divina não ajuda a apaziguá-lo, lembrando que, nesse quadro, usuários e agentes podem estar usando o termo transtorno apenas como um novo nome para a doença, mas enquadrando-a como outra doença qualquer. Tais representações deixam a porta aberta para outras questões: o usuário se pergunta: "por que eu? Por que isso aconteceu comigo?"

O avanço dos psicofármacos, de um lado, foi muito positivo no controle dos sintomas e na qualidade de vida do usuário paciente, porém, de outro lado, foi nocivo para a atenção, o cuidado e o suporte ao sofrimento. Tal avanço fortaleceu uma visão da doença - se tem remédio, então é doença! - como de fundo orgânico, e, embora a psiquiatria anátomo-técnica (Pereira, 2000) queira se isentar de discussões etimológicas e mesmo psicopatológicas, ela reforça uma visão funcionalista, pragmatista, objetivante do transtorno, como se ele pudesse ser isolado do sujeito que sofre.

Aqui, Roland Gori (2004) aponta muito claramente o perigo: a paixão pela causalidade. Isso que dizer que, em uma perspectiva de cientificismo objetivante, de naturalização do humano, todos querem uma causa palpável e plausível, possível de ser isolada, identificada, paixão de encontrar uma razão lógica para o sofrimento, que, não entendido, causa mais sofrimento e angústia. No esforço de buscar uma causa, ou na ilusão de a termos encontrado, esquecemos o principal, que é a dimensão simbólica do sintoma, dimensão significante que vem do fato de se tratar de um sujeito em conflito consigo mesmo. $\mathrm{O}$ sofrimento psíquico é a expressão do conflito entre o corpo pulsional e o ser de linguagem e cultura. Para acolher o sofrimento, a postura freudiana é a de abandono da paixão pela causalidade e o enfoque no sujeito.

O sujeito do sofrimento psíquico não necessita encontrar um causa para resolvê-la, o que seria uma tarefa impossível: "Assim, essa discordância primordial entre o eu (moi) e o ser será nota fundamental que irá ressoar em toda uma gama harmônica das faces da história psíquica, cuja função será resolvê-la desenvolvendo-a" (Lacan, 1966/1998, p. 188).

\section{Demanda, necessidade e ambivalência nas instituições}

O cenário da discussão sobre a psicanálise na instituição pública está em profunda transformação desde o estabelecimento da reforma psiquiátrica, de tal modo que Amarante (1995) afirma ser essa "verdadeira mudança de paradigma". O cenário não é definitivo, uma vez que esse campo se encontra em constante atualização, através de novas pesquisas e de projetos voltados para a área de saúde. Visualizar os aspectos dessa mudança parece ser importante para melhor compreensão do papel da psicanálise dentro da instituição pública. 
Mendonça (2006) afirma que muitas mudanças se deram nesse percurso. No início, houve uma tentativa de modificação dos hospitais psiquiátricos com o intuito de torná-los mais terapêuticos. Em seguida, um movimento mais radical solicitava a extinção desses hospitais, fato que acabou ocorrendo, nos últimos anos, no Brasil.

Segundo Tenório (1999) a reforma psiquiátrica brasileira data de pouco mais de vinte anos, e tem como marca distintiva e fundamental o reclame da cidadania do louco, ou seja, um processo de reinserção social que devolva ao louco seu estatuto de sujeito e sua cidadania; afirma ainda que esse processo tem como objetivo elaborar propostas de transformação do modelo clássico e do paradigma da psiquiatria.

Silva (2005) entende que a reforma psiquiátrica também se compromete com a política pública de saúde mental, na tentativa de implementar um projeto de universalidade, equidade e integralidade da assistência à população. Rinaldi (2000) ressalta, porém, que, de um lado, tenta-se resgatar a individualidade perdida dentro dos manicômios, e, de outro, espera-se que esses sujeitos possam ser reinseridos na sociedade: "do privado ao público ou do singular ao universal, estabelece-se uma linha de continuidade entre o sujeito e o cidadão. Se a noção de sujeito diz respeito à individualidade, a cidadania é o lugar do reconhecimento do sujeito na sociedade" (p. 4).

Nesse contexto de luta pela cidadania do louco, a clínica passou a ficar em segundo plano nos debates acerca do sujeito, chegando-se a ponto de se propor também o fim da prática clínica - algo que não leva em conta as claras diferenças entre a prática psicoterapêutica e psicanalítica e as antigas formas de psiquiatria. Nessa nova configuração da prática psiquiátrica, mais voltada para a atenção psicossocial, a psicanálise tenta sua inserção através dessa clínica que procura o envolvimento do sujeito no processo terapêutico (Rinaldi, 1999).
Guerra (2005) afirma ser necessária uma proposta clínica que articule a subjetividade e a dimensão política da instituição, que a tensão existente entre a assistência para todos proporcionada pela dimensão política e a escuta de cada um, derivada da clínica, acaba por produzir bons frutos, em especial quando essas duas áreas resguardam suas diferenças no campo da ética. Para essa autora, fazer da singularidade clínica uma proposta coletiva não significa universalizar intervenções, mas tomar o particular como orientação na construção das práticas dentro da instituição. Rinaldi (1999) lembra ainda que, se a função política - ou social - e a função terapêutica devem ser diferenciadas, não se pode esquecer que uma não existe sem a outra.

Para se retomar a discussão sobre a dimensão propriamente clínica na assistência prestada nos serviços públicos, parece-nos frutífero resgatar uma distinção proposta na psicanálise (D. T. F. Campos, 1999; Tort, 1992) sobre a diferença entre demanda, necessidade e desejo.

No caso dos usuários, sejam eles portadores ou familiares, a demanda é de cuidado, de sarar, de curar, ou, nos casos crônicos, de alívio ao sofrimento e à sobrecarga de ordem psicológica (Campos \& Soares, 2005). Em psicanálise, entende-se isso como demanda de amor inconsciente. Contudo, a instituição sabe que parte disso, parte do cuidado, está em garantir (ou defender o direito!) a qualidade de vida. Essa dimensão da qualidade de vida é referente ao resgate da cidadania. Acerca desse aspecto, podemos falar em necessidades que devem ser atendidas por uma política pública de inclusão do portador e de seus próximos. O risco é o da ilusão de supor que as necessidades de inclusão do usuário, que sofre as consequências da determinação social de um transtorno mental, são as mesmas necessidades de um cidadão excluído que não necessita de atenção específica. A exclusão tem várias facetas e configura diferentes processos sociais e simbólicos que não se resumem na pobreza material (P. H. Campos, 
1999), ou seja, a demanda é de retornar à vida de antes da doença, mas o de que o usuário necessita são serviços especializados de atenção. Nesse sentido, trata-se, assim como no caso de crianças e adolescentes ou índios, por exemplo, de uma cidadania pleiteada, total ou parcialmente, por outrem. A conclusão a que se pode chegar é que, na assistência, o usuário deve encontrar as condições de entender as novas necessidades, ressignificar sua vida, refazer seus projetos de vida e a relação das necessidades com os direitos e as políticas públicas. Aqui, o cuidado não é clínico, e deve voltar-se para a criação de condições de transformação do usuário em sujeito-de-cidadania. A armadilha está em acreditar que o trabalho de inclusão suprima o trabalho clínico que é feito com a demanda e o desejo. Para a psicanálise, a demanda é o caminho sem o qual não se pode aceder ao desejo que está na base do sofrimento.

Outro aspecto associado ao apresentado acima é que muitas vezes o embate político esquece ou negligencia o fato de que se trata de uma cidadania pleiteada por outros agentes que não o próprio portador. Os profissionais e os conselhos de ordem, em vários episódios, tomam decisões em nome de uma cidadania cuja demanda não emana do próprio sujeito.

Em relação à prática médica, a psicanálise, que já teve grande aceitação nesse campo, hoje se encontra em uma situação desfavorecida. Pereira (2000) analisa que, no início dos anos 80, com o advento do DSM-III (e atualmente o DSM-IV), a psicopatologia médica volta sua atenção para o modelo empírico experimental, abandonando toda e qualquer outra forma de compreender os fenômenos psicopatológicos. Com isso, a psicanálise, assim como outras correntes de pensamento, são excluídas do cabedal de conhecimentos necessários à prática da Medicina. Desse período até os dias atuais, a situação não parece ter se modificado muito.

Assim, o atual quadro da saúde mental aparece como um terreno onde alguns objetivos são comuns à psicanálise e à psiquiatria, e outros são contraditórios. Não será possível para o saber psicanalítico contribuir com a cura propriamente dita dos indivíduos em sofrimento nem tampouco com a adequação destes na sociedade, esta entendida como volta à normalidade, pois tais propostas contrariam a ética da psicanálise. No entanto, o esforço contra a alienação do sujeito e o seu envolvimento no processo terapêutico, como já citado, são ideais comuns às duas áreas (Guerra \& Souza, 2007).

As instituições destinadas ao cuidado com a saúde mental, no nosso tempo, são marcadas pela ambivalência. Para Bauman (1999), a ambivalência no mundo moderno se inscreve na lógica da oposição entre ordem e caos. A instalação da modernidade foi acompanhada de um grande esforço de ordenamento. $\mathrm{O}$ controle foi exercido sobre o corpo, sobre o sexo, a família, a ordem social e a ordem produtiva. Tratava-se de um grande projeto de sociedade ordenada pelo progresso. Para tal, a ordem se estendeu sobre o tempo, o espaço e o corpo (Augé, 1994; Bauman, 1999). A racionalidade da modernidade é a racionalidade da ordem, que visou a instalar um mundo ordeiro no qual a gente sabe como ir adiante, um mundo de certezas, no qual se podem calcular as probabilidades de acontecimento de um evento. O mundo da ciência moderna é um mundo previsível! Contudo, quanto mais a ciência tem sucesso no controle das desordens mentais, por exemplo, mais ela produz, corolariamente, ambivalência. A ambivalência pode ser lida, assim, como um dos traços da modernidade atual.

Então, a ambivalência é inerente à relação entre o usuário-portador de transtorno e a ordem médica, entre sujeito e não-sujeito, entre desejo e alienação. Por tal, as relações entre usuários e profissionais serão, na base, ambíguas: a demanda é suposta (apresentada por um outro que leva, o cuidador) e o sujeito está alienado de seu desejo. 
Também as relações entre os profissionais são marcadas pela imposição (institucional) de uma ordem médica que não é suficiente para produzir os efeitos plenos de norma. Desse modo, o trabalho dito multi, pluri ou transdisciplinar é, por natureza, produto de conflito e produtor de ambivalência. Uma primeira atitude para tornar a psicanálise possível na instituição é o abandono da ilusão ou do desejo de impor uma ordem, qualquer que seja ela.

\section{A confusão das línguas e os profissionais da clínica}

A confusão das línguas é uma expressão que se refere ao fato de os diferentes profissionais da clínica não terem a mesma linguagem para designar os mesmos eventos psicopatológicos e, paralelamente, designarem pelo mesmo nome eventos psicopatológicos bastante distintos entre si. Isso se dá tanto entre profissionais da psiquiatria, da Psicologia e da psicanálise quanto no interior de um único campo disciplinar. A raiz dessa confusão de línguas se inicia, segundo Foucault (1998), desde a origem do termo doença mental, o que induziu à assimilação dos processos mentais aos cerebrais ou neuronais. É a psicanálise que produz a ruptura semiótica que estabelece a identidade dos fenômenos psíquicos, distintos dos neuronais ou espirituais.

As instituições de saúde mental, incluindo desde os centros de atenção especial até os hospitais gerais que têm um ambulatório específico, são tentativas de estabelecer uma ordem em um fenômeno que, por muito tempo, foi definido ironicamente como desrazão, caos, desordem. A escolha do termo disorder emerge como escolha, a de não estar prisioneiro da confusão de línguas que marca o surgimento da clínica psicoterápica, no contexto das então chamadas doenças mentais. Justamente como aponta Foucault (1998), o termo doença induz a ideia de que os fenômenos das alterações psicopatológicas seriam da mesma natureza das doenças do corpo, como se psicopatologia e Medicina fossem da mesma natureza. Um dos principais eixos problemáticos da prática psicanalítica em instituições deriva diretamente da crise da psicopatologia.

Para além da dificuldade de uma definição única de psicopatologia, vários autores (Dalgalarrondo, 2000; Martins, 2005; Paim, 1986) concordam em compreendê-la como um campo do conhecimento, marcado por várias abordagens teóricas, cujo objeto de estudo pode ser vagamente delineado como referente ao adoecer mental. Martins (2005) e Pereira (2000) vão situar seu ethos como próprio do sofrimento psíquico, pela existência do doente/sofrente ou pela vivência subjetiva de quem padece.

Nesse contexto de debate, Fedida e Widlöcher (1990) afirmam que o termo psicopatológico se refere atualmente a uma grande encruzilhada epistemológica na qual se entrecruzam disciplinas científicas heterogêneas, que têm em comum a preocupação com o sofrimento psíquico. Nesse panorama, pode-se assinalar que a psicanálise introduziu rupturas epistemológicas importantes no âmbito da ciência, estabeleceu o modelo a partir do qual as psicoterapias puderam se edificar e se inserir simultaneamente nos campos da ciência e da clínica, transformou a relação entre o normal e o patológico, e, por fim, desestabilizou as psicologias e filosofias da consciência, redirecionando a própria noção de sujeito.

A maneira específica como cada uma das disciplinas heterogêneas define formalmente seu objeto psicopatológico e os procedimentos de pesquisa correspondentes variam de forma marcante, colocando assim o problema das condições de possibilidade para o diálogo intercientífico e para a confrontação crítica. Observa-se, por exemplo, o uso frequente de uma terminologia psicopatológica comum sem que, no entanto, exista um mínimo de concordância quanto aos conteúdos semânticos a que se referem. 
Definida de forma ampla como disciplina que se ocupa do sofrimento psíquico ou, segundo a perspectiva médica, como ciência das doenças mentais, a psicopatologia perde

progressivamente seu papel de fundamento das práticas psiquiátricas,

cedendo

lugar a um

convencionalismo nosográfico que busca responder aos ideais de uniformização de linguagem nesse campo (Pereira, 2000).
O enorme sucesso obtido pelos sistemas operacionais de classificação dos transtornos mentais, cujo paradigma contemporâneo é o DSM-IV, transformou inteiramente o campo da psicopatologia. Definida de forma ampla como disciplina que se ocupa do sofrimento psíquico ou, segundo a perspectiva médica, como ciência das doenças mentais, a psicopatologia perde progressivamente seu papel de fundamento das práticas psiquiátricas, cedendo lugar a um convencionalismo nosográfico que busca responder aos ideais de uniformização de linguagem nesse campo (Pereira, 2000).

Graças a um tipo muito restrito de empirismo e de pragmatismo embutidos em seus pressupostos e ocultos sob o manto de um pretenso ateorismo, o DSM terminou, na prática, por excluir do debate cientificamente autorizado todas as disciplinas cuja abordagem do sofrimento psíquico não repousasse sobre definições explícitas e convencionais de fatos clínicos imediatamente constatáveis. É esse notadamente o caso da psicanálise.

Daí decorre um dos maiores impasses com os quais se defronta a psiquiatria contemporânea. Tendo relegado a psicopatologia a um segundo plano, a psiquiatria encontra-se relativamente despreparada para enfrentar as questões de fundo sobre o sofrimento mental e sobre o estatuto dos modelos decorrentes das diversas formas de abordagem do seu objeto clínico e de pesquisa.

Pode-se dizer, que essa confusão psicopatológica se encontra duplicada ou potencializada pela falta de clareza quanto às funções que cada um pode ou deve exercer. Parece adequado retomar a discussão sobre as relações que a prática analítica estabelece com as outras áreas do conhecimento presentes na instituição pública. Ao analisar essa relação, Alberti (2006) levanta a hipótese de que os profissionais das diferentes áreas de saúde mental que trabalham no contexto público institucional têm ideias bastante diferentes e até contraditórias sobre as funções e o lugar dos profissionais das demais especialidades com as quais se relacionam. Segundo a autora, isso significa dizer que muitos profissionais que trabalham nesse campo não têm o devido conhecimento acerca do que está sendo feito com os seus pacientes quando estes são encaminhados aos seus colegas dentro da própria instituição.

Ainda sobre essa inter-relação, Figueiredo (1996) traz relatos de experiências nas quais as reuniões de área, que são feitas em muitas instituições e se caracterizam por um momento no qual profissionais de diferentes especialidades, mas pertencentes à mesma área clínica (psiquiatras, psicólogos, assistentes sociais, psicanalistas), se reúnem para debater e para trocar informações sobre os pacientes e sobre o andamento dos trabalhos, conseguem muitas vezes minimizar o impacto desse estranhamento entre os diferentes profissionais.

A autora ressalta que seus estudos indicaram dois tipos diferentes de organização dessas equipes de trabalho. As formas de organização hierárquicas e igualitárias, as equipes organizadas através da lógica hierárquica de funções e saberes, tendem a burocratizar a clínica, a verticalizar o poder e o saber, o que pode levar a uma cristalização das práticas clínicas. Já as equipes de orientação igualitária tendem a horizontalizar o poder, o que, muitas vezes, leva à dissolução das especialidades como posições hegemônicas - algo que a autora considera positivo - mas que pode ocasionar a falta de especificidade e confundir as funções a ponto de se perder a referência da clínica (Figueiredo, 2004).

A interação entre os profissionais da clínica é importante, pois os diferentes campos de conhecimento tendem a traçar explicações para os fenômenos clínicos apresentados de acordo com seus próprios referenciais teóricos. Não obstante, o que resta, no final, é a necessidade de lembrar que o fundamental na clínica é "fazer valer o sujeito" (Alberti, 2005). Na dinâmica de um Centro de Atenção 
Psicossocial (CAPS), as práticas psicanalíticas dentro desse local são influenciadas pelos pressupostos da clínica médica, isso porque o diagnóstico e o tratamento medicamentoso acabam tendo grande influência na forma de tratar o paciente (Oliveira, 2004).

Esse ponto de vista, apesar de ocorrer ainda em algumas instituições, parece não refletir totalmente a realidade dos atendimentos psicanalíticos. Sigal (1989) inscreve o diagnóstico psiquiátrico clássico não como forma de compreensão do paciente, mas como forma de cristalização do sofrimento na enfermidade mental classificável, fazendo desaparecer a singularidade do paciente. Por outro lado, Figueiredo (1996) alerta que muitos psicanalistas tendem ainda a levar sua prática clínica do consultório privado para as instituições. Quando mais integrados com o ambiente institucional, abrem mão de tal posicionamento, mas nem por isso precisam deixar de considerar a subjetividade dos sujeitos e suas implicações no processo terapêutico.

É importante considerar que existe uma relação ainda mais truncada entre a psicanálise e as psicoterapias em geral no contexto aqui estudado. Essas práticas estão ainda mais próximas uma da outra dentro da instituição pública. Minatti (2004) afirma que, na maioria de seus atendimentos, o efeito é apenas terapêutico, aliviando ou suprimindo sintomas ou, ainda, situando as pessoas em seu meio. Não obstante ela ser uma psicanalista que utiliza o método freudiano no ambiente institucional, acrescenta que raros são os casos em que se forma uma demanda propriamente dita que dê algum direcionamento mais específico ao tratamento.

Sobre esse ponto, Freud (1919/1996) já assinalava que, na ausência de condições para a prática analítica, é possível ainda ajudar o paciente de alguma forma colocando-o na situação mental mais favorável à solução do seu conflito. Algumas vezes, o analista é obrigado a assumir também a posição de mestre e mentor. Essa concepção nasce a partir dos trabalhos que Ferenczi realiza com pacientes que deveriam ser rejeitados como sujeitos analisáveis. Não se pode desconsiderar a abertura de um campo de trabalho aos psicanalistas dentro das psicoterapias ou dos tratamentos com finalidade terapêutica.

Vários autores (Alberti, 2006; Figueiredo, 1996; Rinaldi, 1999) acreditam que é possível estabelecer uma fronteira entre psicoterapia e psicanálise, com ganhos para o paciente. Nesse sentido, as duas abordagens podem "encontrar uma via que não seja nem da fusão nem da declaração de guerra ou ainda da pura crítica e nem aquela da renúncia em proveito de uma clandestinidade ou refúgio" (Sauret, 2006, p. 40).

Figueiredo (1996) traz outra contribuição em relação à postura do psicanalista dentro da instituição e no trato com os demais membros da equipe de trabalho. Afirma que o psicanalista pode contribuir grandemente para a melhoria dos trabalhos, desde que não se apresente como o portador da boa nova: conhecedor de uma verdade que outros ignoram, mas sim, como mais um aprendiz que ali está para aprender com os demais e para acrescentar seus conhecimentos a fim de melhorar o trabalho.

Em última análise, espera-se seja possível abrir um espaço, dentro da instituição, para que o sujeito se expresse sem que a escuta de seu sofrimento seja orientada por ideais médicos de cura ou de reabilitação (Bueno \& Pereira, 2002). E também que esta não se torne uma escuta compreensiva subordinada à perspectiva do cuidado e preocupada com as questões do sentido, o que a tornaria moralizadora e educativa (Rinaldi, 1999). Esse ideal esbarra muitas vezes na concepção de colegas de clínica que preferem procurar maior conforto no cientificismo, no diagnóstico rápido e na eficácia dos medicamentos, a se arriscarem com técnicas novas que não dependem somente de seus próprios talentos, mas sim, do desejo do paciente e de seu envolvimento no processo (Mazzei, 2001). 
Essa postura que, de início, abre mão do desejo de curar o sujeito, considerando que todo caso é perdido, para só assim ter livre acesso ao inconsciente do paciente, em muitos casos, remete o profissional ao seu próprio desamparo, o que dificulta sua aceitação do método psicanalítico (Alberti, 2006). Nesse particular, é preciso interrogar, com Freud, (1914a/1996) se não são os próprios psicanalistas os responsáveis pela resistência ao método psicanalítico por não conseguirem transmiti-lo de forma adequada e compreensível aos colegas das demais áreas de saúde mental. É claro que essa interrogação de Freud foi feita no começo do século, mas ainda não perdeu a sua atualidade, uma vez que continuamos tentando expandir o saber psicanalítico para os demais profissionais da área de saúde (Alberti, 2006).

Outro fato que chama a atenção é a situação a que os pacientes são levados quando se encontram dentro da instituição. Seu sofrimento acaba sendo institucionalizado, pois esse sujeito transita pelos vários setores da instituição e é atendido por muitos profissionais de diferentes áreas, tenham o mesmo direcionamento ou não. Por fim, é um sofrimento escancarado a qualquer um - profissional - que venha ter contato com esse paciente. Nesse ponto, a singularidade desaparece, e o que resta é apenas mais um caso disso ou daquilo (Oliveira, 2004). Nesse estado de coisas, o psicanalista, ou o psicólogo, é apresentado como um especialista da instituição entendido dos aspectos emocionais e comportamentais do problema. Ele é chamado a dar continuidade à normatização do indivíduo para a sua boa adequação à sociedade (Rosa, 2006).

A chamada institucionalização, que a reforma psiquiátrica quer extinguir, parece bastante resistente e presente quando se observa a vinculação dos pacientes ao CAPS como instituição que os acolhe. É interessante notar que a maioria dos pacientes gosta muito de ser atendido na unidade de saúde e tem entre seus principais receios a impossibilidade de continuar recebendo acompanhamento pelos técnicos do CAPS ou mesmo a possibilidade de receber alta. Não raro os técnicos se deparam com casos em que o paciente obteve melhoras satisfatórias em relação a sua condição anterior, e, no entanto, encontram muitas dificuldades para convencer o paciente a entrar em um grupo de desligamento ou para procurar, no ambiente externo ao CAPS, novas formas de relação e de possibilidades de vida. Podemos destacar alguns casos de usuários que apresentam melhora significativa durante um período de tratamento e, quando se aproxima o período de sua avaliação médica, ocorre uma regressão marcante dessa melhora, com retorno do quadro de sofrimento que o paciente apresentava anteriormente, $\mathrm{o}$ que constitui nítida reação de dependência psíquica da instituição.

Sigal (1989) pensa que os trabalhadores da saúde mental, no seu dia a dia, encontram uma demanda sempre urgente devido à gravidade dos sofrimentos ali experimentados, um vazio que precisa ser de algum modo preenchido, em que é preciso dar respostas rápidas a problemas extremamente complexos, cuja resolução imediata é quase impossível.

Outra questão abordada por Oliveira (2004) diz respeito à uniformização do tratamento dos pacientes, quando a equipe clínica da instituição decide estabelecer um padrão único de tratamento para todos os pacientes ali atendidos. Segundo a autora, essa posição também tende a encobrir as diferenças entres as diversas áreas do saber envolvidas nesse processo - o que não acarreta benefícios - e também mascara a subjetividade e a individualidade dos pacientes, pois, se todos são tratados da mesma forma, não existe espaço para o singular. E, como bem afirma Pereira (2000), a clínica é o espaço de expressão do singular por excelência.

\section{A escuta psicanalítica e a condição transferencial}

A questão do método ou da técnica psicanalítica é palco de grande controvérsia, sobretudo 
visto que algumas instituições psicanalíticas se opuseram à sua difusão para outros meios. O debate ganhou intensidade com o desenvolvimento da escola latino-americana (Martin-Baró, Pichón, Baremblitt, etc) que inegavelmente levou a prática analítica para dentro dos manicômios e de outras instituições. Antes mesmo de examinar a psicanálise de grupo, devemos retomar algumas posições que originalmente tratam da psicanálise individual em instituições ou fora do dispositivo clássico do consultório. Em se tratando de psicanálise, a partir de Freud, essas posições não são antagônicas àquelas necessárias ao trabalho de grupo, ao contrário, contribuem para o desenvolvimento das especificidades deste último.

O termo método psicanalítico é utilizado por Lacan para designar toda forma de prática analítica que seja executada em local que não seja o consultório clínico tradicional (Lacan, 1966/1998). Entretanto, Baremblitt (1982) afirma que a psicanálise está mais para "uma prática social científica composta por uma teoria, com um objeto formal abstrato específico (a estrutura psíquica) e com sua região determinante última (o inconsciente), por um método, por uma técnica e por uma situação experimental própria - a situação analítica". Nessa perspectiva, a prática psicanalítica pode se adequar sem empecilhos ao trabalho institucional.

Bueno e Pereira (2002) definem a situação analítica como a "condição transferencial e técnica particular capaz de sustentar, face a um sujeito que sofre com seus sintomas, o enigma de seu inconsciente e o desejo de elucidação do saber que supostamente ele comporta" (p. 16). Para esses autores, é nesse momento que se torna possível a confrontação do sujeito com as implicações de sua própria fala. E tal situação garante a esse método o status de psicanalítico, não importando se ele se dê no próprio setting ou em outro ambiente onde se pratica a clínica.

A escuta singular da psicanálise é entendida por Rinaldi (1999) como a escuta da articulação significante do inconsciente, e está longe de constituir uma forma de escutar que se subordina à perspectiva do cuidado e se preocupa tão somente com as questões do sentido, o que acabaria acarretando mais uma prática moralizante e educadora. A autora acredita que essa forma de escutar seja a maneira encontrada para fazer advir esse sujeito complexo e singular que surge nos fenômenos da linguagem, nas fendas do discurso de cada um. Dessa maneira, o sujeito não pode ser alheio àquilo que o acomete, vez que esses fenômenos são também eventos de linguagem. É preciso, então, escutar a verdade do sujeito, mesmo que este não a compreenda ou não a aceite como tal.

Por essa razão, a psicanálise tem a responsabilidade de recentrar o lugar do sujeito, pois a noção de responsabilidade é fundamental na dinâmica psicanalítica. Nesse sentido, parece que o discurso do psicanalista é o único a se dirigir propriamente para o sujeito (Alberti, 2005). Rinaldi (1999) ressalta que a responsabilidade da qual a psicanálise trata se distingue da responsabilidade moral, e diz respeito ao sujeito constituído através da linguagem em sua relação de alienação com esta última, sujeito esse atravessado pelos significantes que vêm do Outro. Pode-se inferir, então, que a função da psicanálise é propiciar o aparecimento do sujeito, para que este possa conduzir o seu próprio tratamento, utilizando-se, para tanto, dos mecanismos psicanalíticos: a fala, a transferência e sua capacidade de elaboração simbólica.

Del Volgo (1998) acrescenta ainda que a doença não acontece por acaso, mas vem para pôr em ato aquilo que as palavras não conseguiram expressar e que só poderia ter significado dessa maneira. Assim, não se trata de escutar os fatos ou as causas da doença, nem tampouco a doença, pois o discurso sobre o corpo só alcança seu verdadeiro valor psíquico na relação subjetiva em que este aparece, mas sim, escutar a doença do 
doente, pois só esta tem o poder de, através da complacência da língua, traduzir em palavras o sofrimento pático do sujeito.

Figueiredo (1996) analisa que a transferência é, ao mesmo tempo, o veículo principal pelo qual o tratamento analítico tende a se mover e também a vara cindida que demanda ao analista astúcia e muito cuidado no manuseio, porque o analista, mesmo apenas enunciando a regra fundamental da psicanálise, se coloca na posição daquele que escuta o outro, e isso, de alguma forma, convoca os conteúdos enclausurados no inconsciente do paciente. Nas palavras de Freud (1914b/1996), "o repetir, tal como é induzido no tratamento analítico, implica, por outro lado, evocar um fragmento da vida real, e, por essa razão, não pode ser sempre inócuo e irrepreensível" (p. 167).

Para este trabalho, entenderemos a transferência como a retomada de sentido, em uma nova organização do material significante fonemático e hieroglífico, que havia sido relegado à condição inconsciente. Esse processo ocorre na análise pelo jogo do determinismo transferencial, no momento em que, segundo Gori (1998), elevamos o discurso associativo à categoria de charada, jamais o confundindo com um desenho a ser interpretado. É nesse sentido que o trabalho do psicanalista na instituição ganha uma dimensão ainda mais importante, pois o paciente, na maioria das vezes, se apresenta como um desenho multicolorido, composto pelo diagnóstico médico (do qual os pacientes fazem questão de nos deixar devidamente informados), pela suposta demanda trazida pelos familiares e pelas recomendações da própria instituição acerca do tratamento. $\mathrm{O}$ psicanalista precisa, então, se ater à escuta do sofrimento para poder dar início ao processo analítico. Como afirma Del Volgo (1998), é necessário renunciar à representação visual do fenômeno psicopatológico para que haja a escuta de uma "sonoridade significante do corpo". Para que a realidade psíquica possa ser conhecida pelo clínico, deve-se abandonar a ilusão de pensar que os transtornos trazem respostas satisfatórias aos dilemas sociais e inconscientes do sofrimento.

Podemos ainda afirmar, com Birman (2000), que o desejo continua sendo o substrato bruto a ser escutado e redirecionado nas falas de nossos pacientes, em qualquer contexto ou temporalidade. Até mesmo por isso, parece ser possível colocar em prática aqui a psicanálise praticada por Freud nos primórdios de seu percurso, na qual o objetivo é a ressignificação dos sintomas apresentados pelos pacientes, sem a preocupação normalizadora que perpassa a clínica médica e que atualmente atinge também o campo psicanalítico.

A dificuldade, então, é recuperar a dimensão do singular, que só se torna possível à medida que o sujeito encontra alguém a quem possa endereçar suas palavras, suas dores, seu desejo. É nesse contexto que entra em cena a transferência como veículo de fundamental importância para a prática psicanalítica.

\section{A escuta psicanalítica no contexto institucional}

Em relação à transferência, dentro da instituição, existem outros elementos que participam desse processo em que deve ocorrer o trabalho analítico. Em primeiro lugar, o analista não é a primeira pessoa a escutar o sofrimento do paciente, uma vez que ele necessariamente já passou pela consulta com o médico e já foi acolhido individualmente por um dos profissionais da instituição quando chega àquele local. Destarte, o que se escuta inicialmente, nos atendimentos individuais, é sempre algo do tipo eu já contei a minha história para o médico, ficando a pessoa menos aberta à possibilidade de estabelecer um vínculo através do qual possa emergir a transferência.

Outra questão ainda pode ser colocada: além do analista, do paciente e do inconsciente, entra em jogo a figura da instituição, com suas 
demandas próprias e suas regras, que precisam ser respeitadas, a família do paciente, que normalmente é quem o encaminha ou induz o mesmo a procurar algum tipo de tratamento, além de criar uma demanda que é suposta exatamente por ser derivada não do próprio sujeito, mas daqueles que com ele convivem e a vinculação desse mesmo sujeito à instituição como lugar que o acolhe de maneira diferenciada. Todos os elementos participam e interferem na relação transferocontratransferencial.

Nesse sentido, Figueiredo (2004) afirma que a clínica deve atuar sobre o geral "dado por determinadas diretrizes do campo da saúde mental, como: a reabilitação, a cidadania, a autonomia e a contratualidade, que visam a ampliar as relações sociais dos usuários e a fazer proliferar suas possibilidades" (p. 77). As questões relativas ao singular seriam a junção do particular que compreende o universo dos transtornos mentais com as características intrínsecas de cada indivíduo. O autor afirma que o sintoma não existe sem que o sujeito lhe dê significado, que o constitua através de sua história, de sua fala e de suas peculiaridades. Assim, o diagnóstico e o tratamento se apresentam como instâncias indissociáveis, e um acaba por definir o outro, não restando mais o diagnóstico apenas como definidor do tratamento, mas também o contrário (Figueiredo, 2004).

Deve-se salientar que, no contexto institucional, os pacientes atendidos são classificados como portadores de transtorno mental, desde que o paciente é recebido, nos serviços pós-crise ou pós-urgência. Então é configurado um quadro no qual vários sujeitos concretos (o psiquiatra, o assistente social, o pedagogo, o enfermeiro, o psicólogo, o zelador, o porteiro, etc) vão ocupar, mesmo que não intencionalmente, a voz da instituição. $\mathrm{O}$ discurso institucional tem efeitos normativos, pelo poder que lhe é atribuído (incluindo o poder de cura, fantasiado por pacientes e familiares) no imaginário social, com seus discursos, ideologias e representações da doença, da loucura e dos sofrimentos da alma ou da cabeça. Do ponto de vista sociológico, a instituição é uma entidade tangível. A rigor, se retomarmos Lapassade (1983), cada instituição em particular, cada CAPS, por exemplo, é uma organização que particulariza a instituição de saúde mental. Contudo, do ponto de vista ontológico, para cada paciente, a instituição somente poderia se tornar uma entidade coletiva tangível se lá estivesse estabelecido um grupo social, no sentido restrito desse termo na Psicologia social. Raramente uma equipe de trabalho em uma instituição de saúde mental constitui um grupo, com coesão e interdependência.

Havendo um grupo, poder-se-ia pensar que o paciente encontraria na instituição um outro coletivo (da alteridade), substituto no social do Outro (no sentido lacaniano) ou substituto dos objetos originais internalizados (no sentido que lhes é atribuído tanto por Bion quanto por Pichón-Rivière). Não havendo grupo, o discurso da instituição será composto de um conjunto de discursos fragmentados, sem coesão (que é uma das características definidoras dos verdadeiros grupos, e não das instituições), cuja unidade ou eixo normalmente é o diagnóstico médico. Este, por sua vez, afasta a atenção de todos, inclusive do próprio paciente, do singular que existe em cada sofrimento. Dessa forma, o discurso da instituição engendra a duplicação ou o reforço do sintoma social, que já se encontra em operação: no processo de adoecimento, o imaginário social oferece ao sujeito as figuras da loucura e do sofrimento que são legítimos ou válidos na cultura.

Não é por acaso que a fragmentação do tempo e do espaço é figura privilegiada para manifestar o sofrimento psíquico no nosso tempo; não por acaso, a esquizofrenia faz o paradigma do sintoma social no caso do doente mental: o sujeito que perde a 
cabeça, tem o pensamento desorganizado, desequilíbrio mental ou emocional.

Assim, o discurso da instituição induz ou reifica o sintoma social. Esse discurso, como representante válido e cientificamente atestado do discurso do Outro, vem também carregado do Imaginário cultural que corresponde à condição do louco (Minatti, 1998).

O sintoma social, sendo também formado de fantasias, é passível de fazer emergir o sofrimento (Rosa, 1999). No trabalho de grupo, como veremos adiante no texto, uma primeira fase se constituirá da permissão da expressão ou da emergência do sintoma social para que os sujeitos possam desconstruí-lo e fazer aparecer o espaço do sintoma singular. Podemos então afirmar que, de certa forma, esse discurso é produtor de sofrimento. Ainda assim, a disponibilidade do profissional para escutar tais relatos traz para a esfera do possível a ressignificação do pathos (paixão, padecimento) que tange a cada sujeito.

Do que foi exposto, podemos afirmar que o grupo é um instrumento privilegiado de recriação e de desconstrução de imagens marcadas pela exterioridade, nas quais o eu não se reconhece. Isso é particularmente pertinente no caso de pacientes que apresentaram episódios psicóticos. O grupo representa um recurso metodológico que abre o espaço para o encontro com o simbólico diante de um Alter que responde ao desejo e pelo desejo.

Transportada para a realidade dos CAPS e dos ambulatórios, tem-se uma dinâmica parecida, na qual, muitas vezes, o psicanalista é chamado a atuar em um grupo operativo (costura, artesanato, etc) e ali precisa recolher as falas que não se apresentam como demanda constituída e trabalhar com esse material, possibilitando, através da escuta analítica, o surgimento de elaborações e ressignificações. Fica claro que a atuação do psicanalista na instituição não pode se reduzir à pura reprodução de suas ações em seu consultório privado, pois tal atitude vai de encontro à natureza da clínica que ali se desenvolve, além de torná-la completamente ineficaz por falta de elementos de trabalho (Rinaldi, 1999).

Outras literaturas, como em Costa, (2006), chegam a afirmar que, na maioria dos casos, o que se vê são pacientes cujo discurso sobre seu padecer não passa de monólogo vazio de sentido e desvinculado de sua existência. Nesse quadro, o desafio, então, é recuperar a dimensão do singular. No entanto, quando se estabelece a mediação grupal associada ao trabalho com e da transferência, essas falas passam a ganhar sentido. Os pacientes começam a perceber que naquele espaço poderão ser escutados, emergindo, nesse processo, o desejo.

É interessante lançar aqui o conceito de Birman (2000) quando afirma que o que se pretende com a experiência analítica não é um processo de cura, propriamente, mas a possibilidade de que o sujeito possa relançar seu desejo e se apropriar com isso, de outra maneira, de sua própria história. No aspecto relacionado com a cura, ficam em aberto ainda questões tais como se o sujeito deseja alguma modificação em sua vida, se possui alguma demanda para ser ressignificada, ou ainda se está em condições de participar de tal processo que, desde os tempos de Freud, exige um mínimo de elaboração e de abstração por parte do paciente para que a análise possa ocorrer.

\section{Psicanálise e atendimento em grupo}

É importante ressaltar que os autores citados até este ponto baseiam suas experiências e considerações, em sua maioria, nos 
atendimentos individuais que realizam no contexto institucional. No entanto, essas construções nos ajudam a considerar as possíveis formas de trabalhar a psicanálise de grupo dentro da instituição pública, objetivo último deste trabalho, já que existem muitos pontos em comum entre a psicanálise individual praticada na instituição e a psicanálise de grupo que ora propomos, em especial, as considerações feitas acerca do vínculo social que perpassa toda a clínica inserida dentro da instituição.

O trabalho com grupos de pacientes em CAPS, ou serviços análogos, é marcado pela heterogeneidade na forma de organização dos mesmos, cada qual se estruturando de maneira distinta dos demais. Essas diferentes maneiras de organização podem ser mais bem compreendidas a partir da ótica de Bion sobre grupos, em especial utilizando o seu conceito de suposições básicas, que são as formas mais primitivas de organização dentro de um grupo, e a partir das conclusões de Baremblit acerca da evolução da psicoterapia de grupo. Segundo Bion (1975), as suposições básicas, que podem conviver dentro de um mesmo grupo, surgem como formações secundárias a uma cena primária extremamente antiga, representada em um nível de objetos parciais e associada a ansiedades psicóticas. Quanto mais os sujeitos se encontram envolvidos nessas suposições básicas, mais os grupos operam no nível de mecanismos primitivos.

Baremblitt (1982) estabelece que, na história das técnicas grupais, ocorreu a seguinte evolução na forma de tratamento: primeiro houve a psicoterapia pelo grupo, no qual se utilizavam técnicas de sugestão e identificação para alcançar os objetivos desejados; em seguida, a psicoterapia no grupo, na qual o terapeuta ou analista tratava individualmente cada membro na presença dos demais, e, por último, a psicoterapia do grupo, em que $\mathrm{o}$ inconsciente grupal aparece tal como uma unidade, com seus fantasmas e ansiedades.

No que se refere à nossa experiência de atendimentos semanais a três grupos de pacientes, podemos destacar alguns aspectos específicos dos grupos nos quais trabalhamos e que corroboram as teorias aqui apresentadas.

O grupo de acolhimento parece organizarse sobre a suposição básica de dependência em relação aos terapeutas que conduzem o trabalho. Aqui funciona fortemente o sintoma social, e há grande limite na partilha das vivências ou fantasias. O que parece acontecer é um despejar de figuras da loucura, mesmo que boa parte desses pacientes não seja estruturalmente psicótica ou não esteja em crise, o que não quer dizer que haja uma transferência, tal como entendido no sentido analítico. Pode-se perceber que a demanda explicitada nesse grupo em particular é reprodução da demanda dos familiares que trazem os pacientes até o CAPS. Não aparece, nas falas dos pacientes, qualquer tipo de demanda singular, mas sim, estereótipos de doenças mentais e das suas sintomatologias típicas. Aqui parece pertinente a afirmação de Pichon-Rivière (1986) de que o louco nada mais é que o depositário da loucura familiar. É tanto dessa maneira que esse grupo sempre ocorre em concomitância com outro no qual os familiares - aqueles que acompanham os pacientes - participam e discutem as dificuldades e as possíveis formas de colaborar no tratamento do paciente.

Nos grupos psicoterápicos atendidos, pudemos notar que seu andamento se assemelha ao grupo operativo terapêutico de Pichon-Rivière, no qual a cura propriamente dita constitui a diminuição das ansiedades psicóticas básicas desencadeadas pela regressão infantil; assim, a tarefa do grupo é a resolução das situações de ansiedades criadas pelo próprio grupo, as quais adquirem, em cada membro, características peculiares. O autor afirma que, para isso, é necessária a elaboração, através de sucessivas voltas de espiral, de um esquema referencial comum; esse conceito implica as formas que cada integrante do grupo utiliza em suas próprias vidas ao lidar com seus conflitos. Essa construção de um esquema referencial 
grupal leva a um processo de aprendizagem no qual os integrantes do grupo são levados a fazer uma análise semântica e sistêmica de seus próprios esquemas referenciais ( $p$. 103). Podem, então, restabelecer algumas redes de comunicação prejudicadas durante o processo de adoecimento, destruir a resistência à mudança e reorganizar uma nova etapa da própria mudança e do seu meio.

Outro fator que caracteriza esses grupos psicoterápicos é a diferença na forma de organização, que pode ser percebida de um grupo para outro. Um dos nossos grupos psicoterápicos, que ora chamaremos de Grupo I, pode ser enquadrado na concepção de Baremblit de psicoterapia no grupo, onde ocorrem poucas interações entre os pacientes e as falas são dirigidas ao terapeuta que conduz o trabalho. É interessante notar que esse grupo possui a maioria de seus participantes diagnosticados como esquizofrênicos. Entendemos que, na estrutura psicótica, é mais difícil fazer com que ocorra um redirecionamento da fala para o outro, nesse caso substituto do Outro. Mas, mesmo nesse grupo, tais interações ocorrem, fato que leva a questionar a estrutura psicótica (ou esquizofrênica, na forma do diagnóstico) da maioria de seus integrantes.

Já o grupo que chamaremos de Grupo II se enquadra na psicoterapia do grupo, no qual as falas são dirigidas ao grupo e este responde, gerando elaborações e associações e permitindo ao terapeuta questionar as questões grupais e assim poder também trabalhar as questões individuais com o amparo da mediação grupal. Ocorre, então, a emergência do desejo através da fantasia que é encaminhada ao social. O laço social permite que o outro entre em cena e questione as falas do sujeito através do grupo.

A opção pela sistemática de atendimentos em grupo se justifica pela possibilidade de a interação grupal facilitar a reinserção dos sujeitos na sociedade, recriando um primeiro laço social, ancorado em uma espécie de imaginário grupal, ou seja, há uma recriação de imagens socialmente partilhadas com a cultura, porém em menor escala e menos persecutórias. Podemos destacar ainda a questão da forma de o paciente se comportar no grupo derivar de suas fantasias em relação ao seu grupo familiar, onde o analista pode questionar a articulação entre o grupo internalizado, como aponta PichonRivière, com o grupo real no qual ele agora se encontra. Essa parece ser uma oportunidade de ressocialização do sujeito alienado. É nesse sentido que se pode dizer que a interpretação no grupo tem sua especificidade: apontar o lugar para onde, do ponto de vista singular e simbólico, a fala se dirige.

Assim, o grupo terapêutico pode funcionar como um cenário onde cada sujeito se expressa a partir de seu inconsciente aprisionado em um imaginário que produz mais sofrimento e que, ao mesmo tempo, permite que cada um dos demais participantes observe os efeitos que suas fantasias produzem no vir a ser do grupo (Sigal, 1989). Tais fantasias sustentam as ações, as intenções e os desejos do sujeito, bases do funcionamento do inconsciente. A organização do grupo se dá através de um processo estrutural no qual os sujeitos constituem sujeitos e objetos dessa mesma organização, influenciando o grupo e sendo por ele influenciados.

Parece-nos que o psicanalista não pode perder de vista a finalidade do dispositivo clínico com o qual opera, tendo sempre em mente que é ele o responsável pelo direcionamento - psicanalítico ou não - do processo. Como afirma Stein (1988), embora a colaboração do paciente seja necessária ao processo analítico, "a paternidade da obra cabe ao psicanalista... e a obra é a metamorfose sofrida pelo paciente em sua adaptação à realidade, segundo o desejo do psicanalista suposto conforme à realidade e conforme igualmente à moralidade" (p. 59). Parece certo que, nesse caso específico, essa transformação visada pelo processo analítico não pode deixar de levar em conta a política institucional e o 
conjunto de demandas oriundas do paciente e de seus familiares. A prática vem demonstrar aquilo que outros autores (Figueiredo, 1996; Moffatt, 1984) já apontaram quando asseguram que a psicanálise não pode se estabelecer no contexto institucional tal qual é praticada pelos psicanalistas dentro dos consultórios, mas deve adaptar-se à realidade das demandas com as quais se depara sem, no entanto, deixar de lado sua identidade.

O que a nossa prática vem demonstrando é que cada paciente traz, em sua história, a marca da exclusão e da perda da voz. E quando alguém se coloca em posição de escutá-lo, garantindo que naquele espaço ele terá de volta o seu direito de expressão, isso já se torna terapêutico. No entanto, a simples manifestação falada que gera a catarse não é suficiente para promover a melhora real no sujeito. Nesse momento, entra em cena a figura do terapeuta, que questiona a relação entre a necessidade e o desejo, daquele sujeito, de fazer parte daquele grupo. Os integrantes do grupo psicoterápico são convidados a participar do processo terapêutico e têm o direito de deixá-lo quando bem entenderem. Mas, enquanto estão no grupo, são chamados a falar e a se colocar frente às próprias questões. As pontuações e as construções feitas pelo terapeuta e pelos demais membros do grupo trazem para aquele que fala a condição de se deparar com seus fantasmas.

Outra questão que perpassa os atendimentos é o fato de o grupo funcionar como suporte frente ao desamparo. Quando um paciente fala e o grupo responde, seja corroborando sua fala, seja contestando-a, ele se sente amparado em sua condição, pois não está mais sozinho, tendo agora quem compartilhe seu sofrimento. Nesse ponto, em que o grupo se molda a fim de acolher a demanda daquele indivíduo, o terapeuta pode intervir questionando os fantasmas inconscientes do grupo, para que a questão individual que se tornou grupal através da mediação produza efeitos de pontuação em todos os que dela agora fazem parte. Essa prática nos parece a melhor forma de adaptação do dispositivo freudiano de análise na situação grupal.

Pode parecer estranho falar de desejo em grupos com sujeitos psicóticos, na grande maioria diagnosticada dentro da grande família da esquizofrenia (F20). Mas o que vemos são pacientes que viveram episódios psicóticos ou que apresentam traços desses episódios, no entanto, tem grande parte de sua existência preservada e permeável ao trabalho da transferência. Em certos campos preservados de sua vida, o sujeito consegue, com o suporte do terapeuta e o do grupo, descobrir o próprio desejo e utilizar-se dele como mola propulsora de seu próprio tratamento. Aqui o terapeuta se coloca na posição descrita por Fedida e Widlöcher (1990) como psiquismo auxiliar do paciente.

Em termos práticos, a psicanálise não tem intenção, ou sequer se acha capaz, de devolver a sanidade mental a qualquer paciente que seja nem tampouco tornálo novamente um cidadão - este último entendido como o emblema da normalidade na sociedade atual. A psicanálise não se propõe a ocupar o lugar de agente da ordem, de instrumento de manutenção do status quo da civilização moderna. Sua proposta é dar ao sujeito condições para que ele consiga encarar de maneira diferente da atual sua existência e sua relação com o próprio desejo. Esse suporte não suprime o trabalho de inclusão, pois o campo conjunto da cidadania e da clínica só pode ser construído de modo complementar. 


\section{Denise Teles Freire Campos}

Doutora em Psicopatologia Clínica pela Université de Provence-França, FRA - França.

\section{Carlos Mendes Rosa}

Psicólogo, Pós-Graduado em Psicopatologia Clínica pela Universidade Paulista, São Paulo, SP - Brasil.

E-mail: carlosmendesrosa@gmail.com

\section{Pedro Humberto Faria Campos}

Doutor em Psicologia Social pela Université de Provence, França, FRA - França.

*Endereço para envio de correspondência:

Av. Lineu de Paula Machado, 826 ap. 101 Lagoa, Rio de Janeiro, RJ - Brasil CEP 22 470-040.

E-mail: phd2001@terra.com.br

Alberti, S. (2005). Um estudo, uma denúncia e uma proposta: a psicanálise na interlocução com outros saberes em saúde mental, como avanço do conhecimento sobre o sofrimento psíquico. Revista Latinoamericana de Psicopatologia Fundamental, 8(4), 721-737.

Alberti, S. (2006). A estrutura e as redes em psicanálise. In S. Alberti, Psicanálise e saúde mental: uma aposta (pp. 81-100). Rio de Janeiro: Companhia de Freud.

Amarante, P. (1995). Algumas considerações históricas e outras metodológicas sobre a reforma psiquiátrica no Brasil. In P. Amarante (Ed.), Loucos pela vida: trajetória da reforma psiquiátrica no Brasil (pp. 87-131). Rio de Janeiro: FIOCRUZ.

Augé, M. (1994). Não-lugares. São Bernardo do Campo, SP: Papirus.

Baremblitt, G. (1982). Grupos: teoria e técnica. Rio de Janeiro: Graal.

Bauman, Z. (1999). Modernidade e ambivalência. Rio de Janeiro: Jorge Zahar.

Bion, W. R. (1975). Experiência com grupos. São Paulo: EDUSP.

Birman, J. (2000). Subjetividade, tempo e psicanálise. Revista Latinoamericana de Psicopatologia Fundamental, 3(4), 11-30.
Bueno, D. S., \& Pereira. M. E. C. (2002). Sobre a situação analítica: a experiência de psicoterapia psicanalítica no hospital universitário da Unicamp. Pulsional: Revista de Psicanálise, (157), 15-24.

Campos, D. T. F. (1999). Demande d'enfant: une écoute psychanalytique. Cliniques Méditerranéennes, (61), 108-119.

Campos, P. H. F. (1999). Parâmetros para uma concepção psicossocial da exclusão. Revista Fragmentos de Cultura, 9(6), 1238-1258.

Campos, P. H. F., \& Soares, C. B. (2005). Representação da sobrecarga familiar e adesão aos serviços alternativos em saúde mental. Psicologia em Revista, 18(11), 219-237.

Costa, A. (2006). Uma experiência de clínica institucional. In S. Alberti, Psicanálise e saúde mental: uma aposta (pp. 155-165). Rio de Janeiro: Companhia de Freud.

Dalgalarrondo, P. (2000). Psicopatologia e semiologia dos transtornos mentais. Porto Alegre: Artes Médicas.

Del Volgo, M. (1998). O instante de dizer. São Paulo: Escuta.

Fedida, P., \& Widlöcher, D. (1990). Présentation. Revue Internationale de Psychopathologie, 1, 3-4. 
Figueiredo, A. C. (1996). Vastas confusões e atendimentos imperfeitos: a clínica psicanalítica no ambulatório público. Rio de Janeiro: Relume Dumará.

Figueiredo, A. C. (2004). A construção do caso clínico: uma contribuição da psicanálise à psicopatologia e à saúde mental. In Revista Latinoamericana de Psicopatologia Fundamental, 7(1), 74-86.

Foucault, M. (1998). O nascimento da clínica. São Paulo: EPU.

Freud, S. (1996). História do movimento psicanalítico. In S. Freud, Edição standard brasileira das obras de Sigmund Freud (Vol. 14, pp. 169-191). Rio de Janeiro: Imago. (Trabalho original publicado em 1914a)

Freud, S. (1996). Linhas de progresso na terapia psicanalítica. In S. Freud, Edição standard brasileira das obras de Sigmund Freud (Vol. 17, pp. 109-123). Rio de Janeiro: Imago. (Trabalho original publicado em 1919)

Freud S. (1996). Recordar, repetir e elaborar. In S. Freud, Edição standard brasileira das obras psicológicas completas de Sigmund Freud. Rio de Janeiro: Imago. (Trabalho original publicado em 1914b)

Gori, R. (1998). A prova pela fala: sobre a causalidade em psicanálise. São Paulo: Escuta.

Gori, R. (2004). Lógica das paixões. Rio de Janeiro: Companhia de Freud.

Guerra, A. M. C. (2005). A psicanálise no campo da saúde mental infanto-juvenil. Psyquê, 9(15), 139-154.

Guerra, A. M. C., \& Souza, P. V. (2007). A reforma psiquiátrica e psicanálise: diálogos possíveis no campo da inserção social. Recuperado em 26 de abril de 2008, de http://www. psicolatina.org/Cinco/reforma.html

Lacan, J. (1998). Propos sur la causalité psychique. In J. Lacan, Écrits (pp. 151-193). Paris: Seuil. (Trabalho original publicado em 1966)

Lapassade, G. (1983). Grupos, organizações e instituições. São Paulo: Francisco Alves.

Martins, F. (2005). Psicopathologia II: semiologia clínica. Brasília, DF: Ed. da UnB.

Mazzei, D. (2001). O desafio do psicanalista na instituição psiquiátrica. Revista Latinoamericana de Psicopatologia Fundamental, 3, 61-65.

Mendonça, M. C. A. (2006). As intervenções nas residências terapêuticas: o que a psicanálise tem a dizer sobre essa clínica? Recuperado em 12 de março de 2008, de www. opcaolacaniana.com.br/n2/textod

Minatti, S. P. (1998). O discurso e o laço social dos meninos de rua. Recuperado em 15 de março de 2008, dehttp://www.scielo. br/scielo.php?pid $=$ S0103-65641999000200013\&script $=$ sci arttext

Minatti, S. P. (2004). A criação do campo psicanalítico na instituição. Revista Latinoamericana de Psicopatologia Fundamental, 7, 20-39.

Moffatt, A. (1984). Psicoterapia do oprimido. São Paulo: Cortez.

Nasio, J. D. (1999). Como trabalha um psicanalista. Rio de Janeiro: Jorge Zahar.

Oliveira, I. M. A. (2004). O caso clínico na instituição pública: polifonias desejantes. Revista Latinoamericana de Psicopatologia Fundamental, 7(3), 82-93.

Paim, I. (1986). Curso de psicopatologia. São Paulo: Ed. Pedagógica e Universitária.

Pereira, M. E. C. (2000). A paixão nos tempos do DSM: sobre o recorte operacional do campo da psicopatologia. In R. A. Pacheco Filho, N. Coelho Júnior \& M. D. Rosa (Orgs.), Ciência, pesquisa, representação e realidade em psicanálise (pp. 119162). São Paulo: Casa do Psicólogo.

Pichon-Rivière, E. (1986). O processo grupal. São Paulo: Martins Fontes.

Rinaldi, D. L. (1999). Clínica e política: a direção do tratamento psicanalítico no campo da saúde mental. Recuperado em 12 de março de 2008, de www.interseccaopsicanalitica.com.br

Rinaldi, D. L. (2000). O desejo do psicanalista no campo da saúde mental: problemas e impasses da inserção da psicanálise em um hospital universitário. Recuperado em 12 de março de 2008, de www.interseccaopsicanalitica.com.br

Rosa, M. D. (1999). O discurso e o laço social e os meninos de rua. Psicologia USP, 10, 205-217.

Rosa, M. D. (2006). A psicanálise e as instituições: um enlace ético-político. Revista Ágora, 9, 35-48.

Sauret, M. (2006). Psicanálise, psicoterapias, ainda... In S. Alberti, Psicanálise e saúde mental: uma aposta (pp. 21-40). Rio de Janeiro: Companhia de Freud.

Sigal, A. M. (1989). Psicanálise, grupos, instituição pública. Revista Percurso, 2, 42-44.

Silva, M. B. B. (2005). Responsabilidade e reforma psiquiátrica brasileira: sobre a relação entre saberes e políticas no campo da saúde mental. Revista Latinoamericana de Psicopatologia Fundamental, 8, 303-321.

Soller, C. (2007). O inconsciente a céu aberto da psicanálise. Rio de Janeiro: Jorge Zahar.

Stein, C. (1988). O psicanalista e seu ofício. São Paulo: Escuta.

Tenório, F. (1999). A reforma psiquiátrica brasileira, da década de 1980 aos dias atuais: história e conceitos. Recuperado em 2 de maio de 2008, de www.scielo.org

Tort, M. (1992). Le désir froid. Paris: Découverte. 